\title{
Data Acquisition Using IoT to Monitor Coal Mining Environment
}

\author{
Savitha $\mathrm{G}^{1, *}$, Deepak N A ${ }^{2}$, Deepak D J ${ }^{3}$ \\ ${ }^{1,2}$ Department of Computer Science and Engineering, RVITM, Bangalore-560076, India \\ ${ }^{3}$ Department of Information Science and Engineering, RVITM, Bangalore-560076, India \\ *Corresponding author.Email:savithamadhusudan@gmail.com
}

\begin{abstract}
Coal is one of the most important non-renewable resource which contributes to majority of power production and used in many industries. The study here presents an innovative, efficient method needed to increase the mining productivity and reduce costs while also considering worker safety. In underground mining, many parameters such as toxic gases released, temperature, air pressure, humidity and fire must be controlled. The proposed system makes use of Internet of Things (IoT) technology in the coal mining environment to build an effective safety system. The system consists of a network of sensors that are used in different places of the mining environment to collect real time data. Arduino senses its environment by processing feedback from a variety of sensors. The results demonstrate that the real time data collected can be used to detect changes in the environment and raise an alarm or message to the end user to avoid disasters.
\end{abstract}

Keywords: Arduino, Coal Mining, Global warming, Internet of Things, Wireless Sensor Networks.

\section{INTRODUCTION}

Our country relies heavily on coal as a natural resource. Coal is primarily used to generate power. Coal is also used in many industries like steel, and cement, as well as a variety of industrial applications. It is said that coal will contribute significantly to a country's economic development. India's energy future and growth are inextricably linked to mining and using coal, the country's most plentiful, cheap, and dependent energy source. However, coal mining can lead to several dangerous situations such as increased temperature and high humidity, as well as the emission of toxic gases. As a result, many lives have been lost, and resources have been depleted. There is no effective method of detection of emergency situations occurring in coal mines. Coal mining has historically been a hazardous operation. Underground mining is a subcategory of the mining industry in which all parameters such as coal, temperature, air pressure, humidity, and fire must be controlled. Although the safe output level of a coal mine is low, disasters in coal mines occur regularly, often resulting in fatalities. Since disasters in coal mines are caused by the complexities of the mine environment and the variety of tasks performed in a coal mine, it is critical to manage and control the mining environment [4].
With the constant expansion of mining areas and depth in coal mines, many lane ways become blind areas with numerous hidden hazards. It is inconvenient and time-consuming to lay costly cables. These situations create a hazardous working atmosphere for employees and put their lives in danger. As a result of this, workers either quit coal mine jobs or unwilling to work in such dangerous environment. This is causing a slew of issues with the coal mining industry's labor supply. Thus, worker safety in a coal mine has become as critical problem that must be tackled. It is extremely difficult for humans to constantly track all environmental conditions in a coal mine. However, this mission can be easily accomplished by the use of very cost-effective sensors located in various strategic locations in coal mines. The proposed model makes use of extremely low-power and energy-coherent sensors to track temperature, humidity, and any unfavorable gases emitted. The primary issue is to prevent the frequent accidents that occur in coal mines as a result of insufficient maintenance and control of mining activities. The proposed work discusses the communication issues and safety concerns in underground mines. The necessity of device perception and real-time data evaluation is also briefly addressed. The system designed is low cost, easy to implement and collects real time data which can be used to prevent accidents. Most of the previous work discusses only 
about the different types of sensors and the data generated by the sensors. The proposed work gives a comprehensive solution by providing the details of the entire architecture, system design and the implementation. Since the implementation is already done in the virtual laboratory environment, the same setup can be easily extended to a real time mining environment [5].

The remaining paper is structured as follows: Section 2 describes the related methods and approaches, Section 3 gives the detailed description of the proposed method, Section 4 provides the details of the system design, Section 5 describes the implementation details and results, and Section 6 concludes the paper.

\section{RELATED WORK}

Normally industrialized accidents occur in dangerous environments like coal mines. As a result, the consequences may be serious, resulting in degradation of the environment and loss of property and life. Therefore, hazardous environmental protection and security are more important in industrial sites for a variety of reasons. Some of the works related to coal mining safety using different technologies are described in this section.

Alfonso et al. [1] proposed an optimization approach for the implementation of wireless sensor networks considering ground level mining to detect gases. They suggested a two-stage solution for reducing evaluation costs while increasing the lifespan of Wireless Sensor Networks. Anas et al. [2] proposed and implemented a framework for real-time gas monitoring. Additionally, they listed the various gases present in the coal mine atmosphere and their impact. Additionally, their work specifies the appropriate limit for the gases. Blasting and drilling activities, coal explosions, and vehicular traffic are the primary sources of air pollution. Nitrogen oxides and sulphur oxides are the primary contaminants. Coal fires are also a significant problem.

Ramesh et al. [3] suggested a method for continuously monitoring the physiological variables of personnel who work in high altitude places. They introduced a device that tracked the physiological variables of staff at high altitude in real time. The entire device was viewed in laboratory view. Gas leak detection is a method that utilizes numerous sensors to locate potentially dangerous gas leaks utilized in nuclear power plants. One of the most significant negative impacts of mining on water is Acid Mine Drainage (AMD). Environmental effects and consequences of AMD, and a brief discussion of different treatment methods using sensors and IoT is discussed in [6]. In Kumar et al. [7] the author suggested a concept based on the MSP430. Numerous parameters such as temperature, humidity, gas, and smoke are tracked in a coal mine. A Zigbee transceiver is installed in the center position, and the climate state is operated through the motor.
In Lihui et al. [8] the author implemented a device in which sensor nodes collect temperature, humidity, and methane values from the coal mine and send the data to an ARM controller for processing; Zigbee is used for communication. If any value goes beyond threshold, an SMS is sent to ensure the workers' safety. Madhu et al. [9] created a framework for controlling coal mine safety by tracking the temperature, humidity and the presence of carbon dioxide in the environment. If an unknown situation arises, a message is sent to the forest and fire departments via GSM. Ashish et al. [10] identified a device that utilizes an ARM processor and a variety of sensors, including a temperature sensor, a humidity sensor, and a gas sensor. A near-infrared sensor is installed to track the conditions. Wakode et al. [11] proposed a device that would be primarily used to detect hazardous gas concentrations in coal mines using Zigbee framework.

Li et al. [12] states evaluation techniques for monitoring and communication networks by taking into account IoT and salient features of acquiring data and its processing. Hesedahl et al. [13] provides deep knowledge about various standards for anomalies detection and noise reduction by incorporating web services into hardware device to sync data and events generated. Stoyanova et al. [14] illustrates state of art theoretical models used in digital world and challenges, frameworks used in privacy preserving environment to secure data using end-to-end encryption.

Gupta et al. [15] demonstrates how data can be collected using network models and open access software in a cloud environment to develop low cost and efficient system by evaluating with various test cases. Supreetha et al. [16] developed a framework to study the machine state and its condition with the help of sensors and draws the salient parameters to communicate with edge server to automate the system using decision support system. Aditi et al. [17] proposed coal mine safety monitoring and alert system to save the life of skilled miners. Factors which cause life threat during mining are analyzed and automated alarm system is developed using IoT and various sensors.

\section{PROPOSED METHOD}

The proposed method utilizes the dynamic nature of the Internet of Things, its well-distributed networking, and the concurrent interaction of several devices for the processing, study, and exchange of data. These characteristics distinguish IoT technologies from the others and elevate it above previous intelligent systems. The proposed method is used to build IoT-based early warning systems.

To effectively avoid mine accidents and to improve protection, the device must meet the following requirements: 
- Aid in effective monitoring data.

- Trace miners inside the mine.

- Instantaneous knowledge sharing.

Mine welfare systems powered by the Internet of Things seamlessly combine gas sensing, tracking, and miner tracking to create an innovative safety loop powered by analytics. The system based on Internet of Things makes use of PLX-DAQ to relay data from sensors connected to Arduino module. Thus, this type of device integration has the potential to detect and decrease major accidents in the mining environment [24].

The lack of communication and information sharing between machines, miners and management makes rapid response to emergencies in underground mines difficult. As a result, unification based on the IoT principle is needed for successful data collection, analysis, and detection of irregular events [25]. The integration of various technologies to create an integrated device using IoT for underground coal mines is depicted in Figure 1. The IoT based architecture is composed of four distinct layers: vision, network, middleware, and application. Each layer serves a distinct purpose within the IoT's overarching structure. The vision layer provides event identification and early deterrent systems for subterranean coal mines through different types of sensors like temperature, humidity, gas, flame, etc. The network layer consists of an integrated connection of sensors and devices that are connected to a centralized system. The middleware consists of the software applications required for collecting and synthesizing data. The Application layer is responsible for sending appropriate signals and messages during accidents and unfavorable situation [26-28].

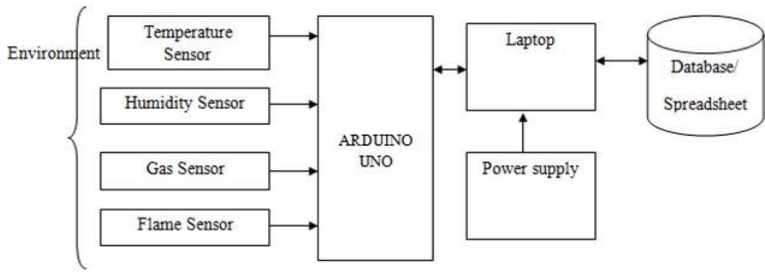

Figure 1 Internet of Things (IoT)-based integration of technologies.

\section{SYSTEM DESIGN}

This section describes the proposed system's architecture. Various hardware and software requirements of the system are discussed in detail. A suitable work environment is created with all necessary components for system development and testing. Then the system was evaluated in its intended environment. This section also details the construction of a hardware system step by step, followed by software design and implementation.

\subsection{System Hardware Design}

The hardware related to monitoring system is composed of many components. It includes boards like Xbee, Arduino, and a Zigbee USB interface board. It also consists of LCDs (liquid crystal displays), various sensors, and other small electronic components. This section provides an in-depth examination of each of these components and their functionality.

\subsection{Arduino}

Arduino is a free and open-source hardware and software platform based on a microcontroller that is incredibly simple to use. Arduino is a low-cost control board that is simple to program and capable of connecting to a wide range of hardware devices. Arduino senses its environment by processing feedback from a variety of sensors and reacts to it. Numerous Arduino boards are available in the market, including the Arduino UNO, Arduino Leonardo, Arduino Due, Arduino Yun, and Arduino Mega [29-33].

The Arduino UNO board used in the experiments is a purpose-built circuit board used for programming and prototyping Atmel microcontrollers. The Arduino Programming Language (based on Wiring) and the Arduino development environment are used to program the microcontroller on the board (based on Processing). It is reasonably priced and can be powered directly from a computer's USB port or from an AC-to-DC adapter or battery.

The Arduino UNO features 14 digital input/output pins (six of which are PWM outputs), six analog inputs, a $16 \mathrm{MHz}$ crystal oscillator, a USB link, a power jack, an ICSP header, and a reset button. The Atmega328 has a flash memory of $32 \mathrm{~KB}$ for storing programs and boot loader uses $0.5 \mathrm{~KB}$ of memory. Each of the 14 digital pins, which work at $5 \mathrm{~V}$, can be used as an input or output.

These digital pins have predefined functions. For example, pins 0 and 1 are used for receiving and transmitting data, whereas pins 2 and 3 serve as external interrupts that can be programmed to cause an interrupt on a low value and a rising or falling edge. Three, five, six, nine, ten, and eleven pins have eight-bit PWM performance, while ten, eleven, twelve, and thirteen pins support SPI communication. Each of the six analog pins can be used as an analog input, providing a resolution of ten bits (1024 different value). These pins are used to calculate voltages ranging from zero to five volts.

\subsection{Temperature Sensor}

The pin diagram for the LM35 is depicted in Figure 2. As a temperature sensor, the circuit will read the ambient temperature and relay it to us in degrees Celsius. The LM35 is a low voltage integrated circuit that operates 
at approximately $+5 \mathrm{VDC}$. This is perfect since the Arduino's power pin outputs $5 \mathrm{~V}$.

The IC only has three pins: two for control and one for the analog output. The output pin generates an analog voltage that is proportional to the Celsius (centigrade) temperature in a linear fashion. Pin 2 has a voltage output of one millivolt per 0.1 degree Celsius $(10 \mathrm{mV}$ per degree). Thus, to obtain the degree in Celsius, take the voltage output and divide it by ten [34-35].

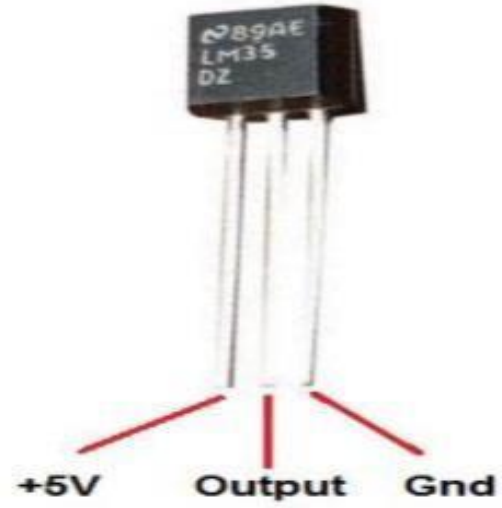

Figure 2 Temperature Sensor LM35

\subsection{Humidity Sensor}

DHT22 is a humidity sensor based on capacitive sensor element. Its reliability and stability are ensured by the use of an exclusive digital signal collection technique and humidity sensing technology. Its sensing elements are connected to a single-chip computer with an 8-bit memory. Each sensor in this model is temperature compensated and calibrated in an accurate calibration chamber [36]. The calibration coefficient is stored in the form of a program in the OTP memory, and when the sensor detects, it will retrieve the coefficient from memory. DHT22's small size, low power consumption, and long transmission distance $(20 \mathrm{~m})$ make it suitable for a wide variety of harsh application scenarios. Single-row packaging with four pins simplifies attachment. Figure 3 shows the DHT22 humidity sensor with pin details.

\begin{tabular}{|lc|}
\hline & DHT22 pins \\
\hline 1 & VCC \\
2 & DATA \\
3 & NC \\
4 & GND \\
\hline
\end{tabular}

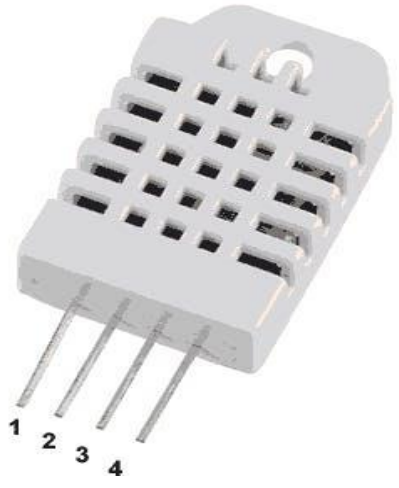

The DHT22 sensor is capable of reading humidity values ranging from 0 to 99.9 percent with a precision of $+/-2 \%$ and temperature values ranging from -40 to $125^{\circ} \mathrm{C}$ with a precision of $+/-0.5^{\circ} \mathrm{C}$. At high temperatures, the humidity accuracy increases to $+/-5$ percent.

Polling the sensor faster than once every two seconds is not permitted; otherwise, data errors can occur. If incorrect readings readings are received (such as 999.00), then increase the gap between reads. A threesecond delay is used in the proposed system.

\subsection{Gas Sensor}

The MQ-6 Gas Sensor is a component of gas detection equipment used to detect Propane gas in residential, commercial, and industrial settings. This sensor is compatible with all Parallax microcontrollers and is an excellent addition to any project that requires the presence of propane to be detected. Figure 4 shows the Mq-6 Gas Sensor [37].

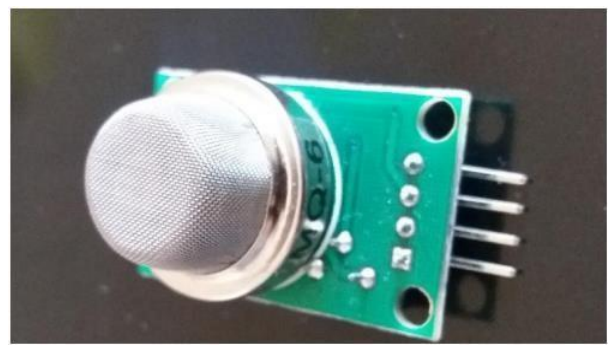

Figure 4 Gas Sensor MQ-6

Nickel oxide-based gas sensors are available in a variety of configurations. Gas sensors may be optical or electrical in nature. The majority of gas sensors operate on the premise that when the sensor reacts with the gas, the sensor's surface changes, resulting in changes in the sensor's optical and/or electrical properties.

The MQ-6 gas sensor's sensitive material is $\mathrm{SnO}$, which has ductility in pure air. When the flammable gasoline is present, the conductivity of the sensor increases with the gas concentration. The MQ-6 gas sensor is extremely sensitive to propane, butane, and liquefied petroleum gas. Additionally, it responds to natural gas. The sensor can be used to detect a variety of flammable gasoline, most notably Methane. It is inexpensive and appropriate for a variety of evaluations. Some of the features are given below:

- High sensitivity to LPG, iso-butane and propane

- Small sensitivity to alcohol and smoke

- Fast response

- Wide detection range

- Stable performance and long life

- Simple drive circuit

Figure 3 Humidity sensor DHT22 


\subsection{Flame Sensor}

The flame sensor may be used to detect flames or other wavelengths of light between 760 and $1100 \mathrm{~nm}$. The flame sensor probe angle is 60 degrees, the flame range is extremely sensitive, and the module is stabilized with two M3 mounting holes. The flame sensor operates between -25 and 85 degrees Celsius. Figure 5 shows the Flame sensor with three pins.

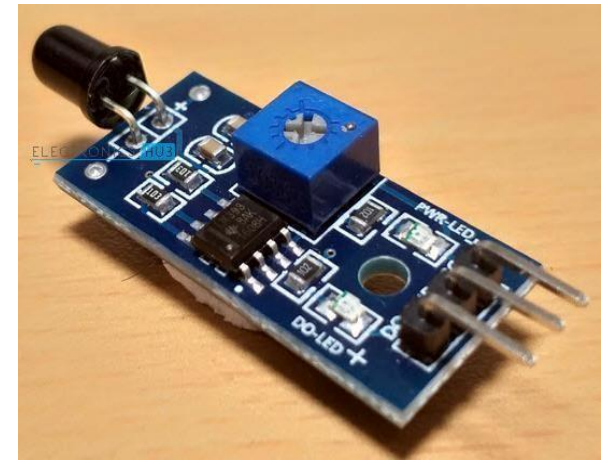

Figure 5 Flame sensor

\section{IMPLMENTATION AND RESULTS}

This section describes the hardware and software implementation details along with the results obtained.

\subsection{Hardware Implementation}

To validate the built real-time evaluation and security system based on a wireless sensor network, a laboratorybased contrived mining environment is set up and various events are simulated. As a first step, we built the entire system on a breadboard, as illustrated in Figure 6.

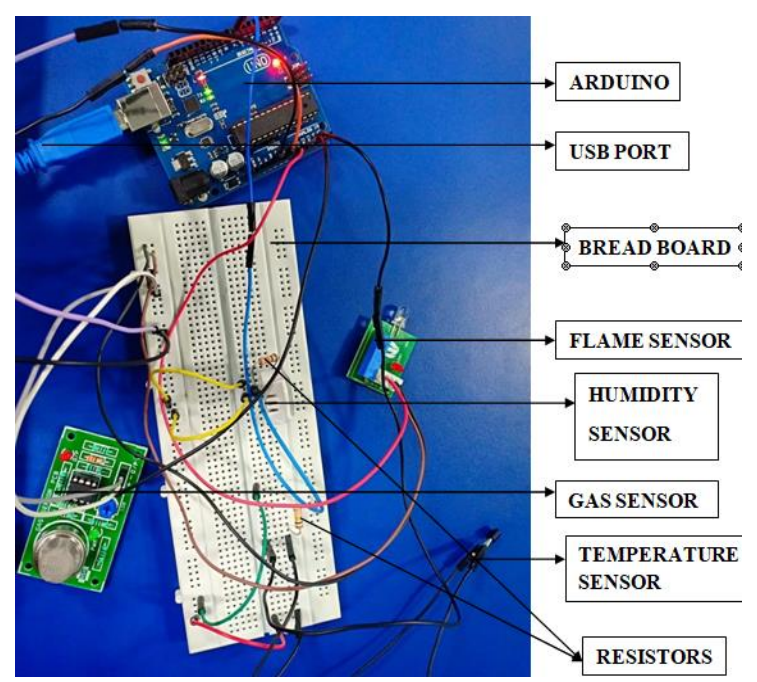

Figure 6 Sensor Unit of Monitoring System using Breadboard

The following components are used in the setup

1. Arduino UNO Board

2. MQ-6 gas sensor

3. Temperature and Humidity Sensor - DHT-22
4. Flame Sensor

5. Resistors

6. Bread Board

The following sub-sections describe the various tools, directives, communication links, data acquisition software and system requirements used in the implementation of the system.

\subsubsection{PLX-DAQ}

PLX-DAQ is a software tool for getting data from microcontroller to Microsoft excel. The controller transmits data in a particular format to the serial port on the device. In Excel, a Visual Basic for Applications (VBA) macro containing a serial port control is used to accept data from the serial port, interpret it, and position it in the spreadsheet, among other things. The type of actions to be taken is communicated to the PLX-DAQ through the Directives.

\section{Serial Communications}

The controller is communicated through the serial COM ports on the device. PLX-DAQ is capable of handling up to 128,000 Baud speeds. If communication is done via USB, several of these devices build a virtual COM port that can be accessed just like a standard COM port. The programming software can indicate which port it is using, or Windows' Device Manager can be used to display the available ports. This model supports only COM Ports 1 to 15.

\section{Speed Limitations}

Serial data, including Start and Stop bits, is transmitted one bit at a time. The term "9600" refers to the capability of sending a byte at a rate of 9600 bits per second. A byte (or character) is ten bits long, including the start and stop bits. This will take $1 / 9600 * 10=1.04$ $\mathrm{mS}$ or.00104 seconds at 9600 baud. With a string such as "DATA,75,76" which contains ten characters plus a carriage return (CR), will take $11.44 \mathrm{mS}$ or 0.0114 seconds to transmit.

This application can only accept and use the data as fast as the program can run. On slow computers, it may not be able to process the data fast enough to perform real-time analysis. Performing real-time analysis depends on the speed of the computer $(223 \mathrm{MHz}$ or $1.2 \mathrm{GHz})$, the rate at which data is being sent from the BASIC Stamp (once a second or every 10ms) and how Excel is using the data (just placing in rows or performing calculations while the data is arriving). If high speed data in real time is required along with generating graphs, it is best to place the graph on a second Excel worksheet and not view it. Viewing a graph will slow the processing time considerably. PLX-DAQ has a 5000 character buffer in the event data arrives faster than it can be processed by Excel. 


\subsubsection{System Requirements}

The minimum system requirements for setting up the proposed system are given below:

- Windows 7 or higher.

- Microsoft Office 2007 or higher.

- Communications port for programming and data

- Microcontroller hardware and editor.

\subsubsection{Excel Macros and Security}

This section gives the details of using Excel macros and security settings. Due to the malicious nature of some VBA macros, Microsoft has security features associated with the use of macros.

- Upon starting the spreadsheet, Excel may ask if you wish to allow the macro to run. For PLX-DAQ to operate you will need to allow it.

- Excel may be set for "High" security and Excel will not ask about running macros, nor will it allow macros to be run. Set security to "Medium" to allow Excel to ask about running macros. "Low" is NOT recommended for security reasons. This can be done in the tools bar (ToolsMacro- Security). Excel must be closed and PLX-DAQ spreadsheet must be reopened for changes to take effect as shown in Figure 7.

Once the spreadsheet is loaded the interface should open automatically, or pressing CTRL-q on the keyboard will open the interface.

- The settings may be used to select the COM port and the Baud rate for the data.

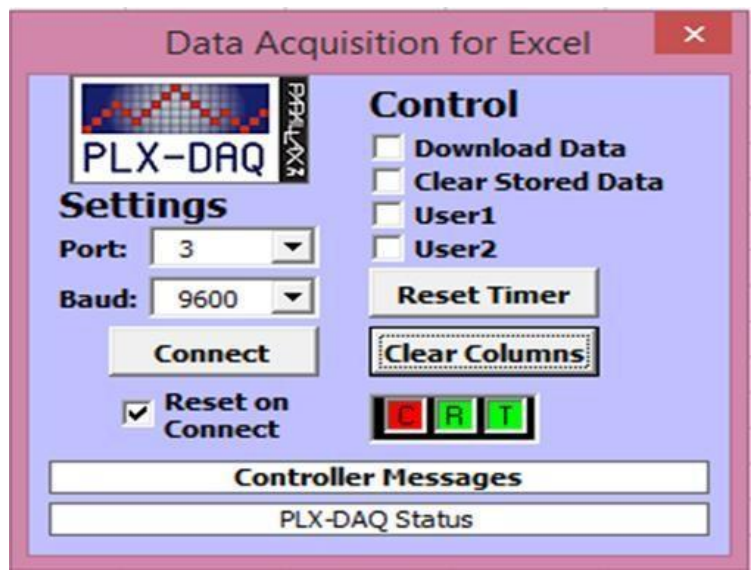

Figure 7 Data Acquisition for Excel

- Clicking the Connect button will connect on the Specified COM port at the specified baud rate ( 8 bits, no parity, and 1 stop bit). Disconnect by clicking it again. The data communication indicators will indicate:

- $\quad$ Not Connected - Red C

- Connected - Green C

- $\quad$ Data Received - Red R
- Data Transmitted - Red T

- Use the Clear Columns button to clear columns A$\mathrm{J}$ (all rows except row 1) or the number of columns data was placed in (up to 26).

- Checkboxes are used for interactivity. The controller can read the checkboxes using directives.

- Download Data can be used to dump stored data for retrieval dependent on user's controller code.

- Clear Stored Data can be used to clear any stored data dependent on user's controller code.

- User1 and User2 are user defined checkboxes and may be labeled by your controller.

- Reset Timer will reset PLX-DAQ's timer to 0 which is accessed using the TIMER directive.

\subsubsection{PLX-DAQ Limitations}

Some of the limitations of using PLX-DAQ tool are described below:

- PLX-DAQ can accept 26 comma-separated values for use in Excel.

- PLX-DAQ will always place incoming data on the 1 st sheet of your workbook. Any number of additional sheets and charts can be created, but PLX-DAQ will use the first in the tabbed-list for incoming data.

- If high-speed data is being plotted, it is recommended to place charts and graphs on separate sheets. Viewing of charts and graphs as data arrives will dramatically slow the processing of incoming data.

- Sharing of modified PLX-DAQ spreadsheets with special graphs or calculations can be done, but the enduser has to installed PLX-DAQ to use the data acquisition features.

- Distribution of modifications to the PLX-DAQ macro is not authorized under the name of PLX-DAQ or other names without consent of participating companies.

\subsection{Results}

This section shows the results of the proposed implementation. 


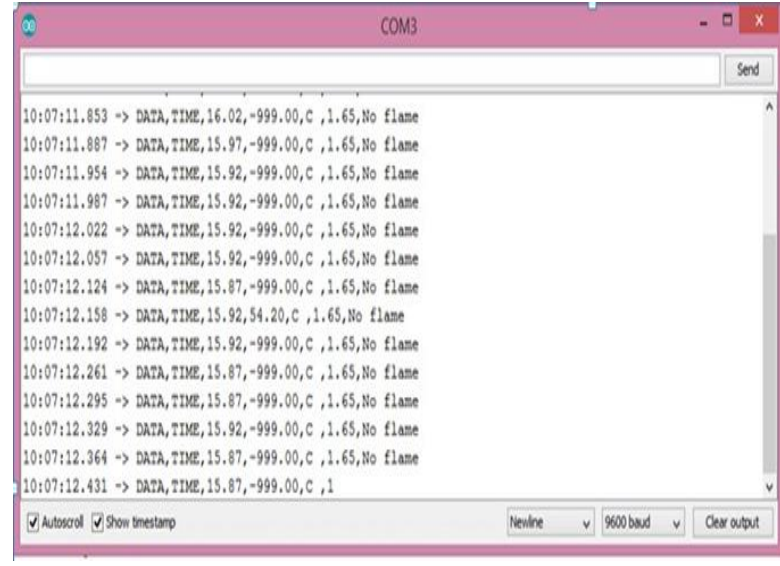

Figure 8 Data of Sensor Nodes

The real time data coming from different sensors can be seen by using COM port. Figure 8 shows a sample screen shot of the data coming from different sensors. This real-time data can be analyzed to get useful information about the mining environment, detect unfavourable conditions and prevent accidents.

Figure 9 shows the software interface PLX-DAQ which can be used to read real time data coming from different sensors.

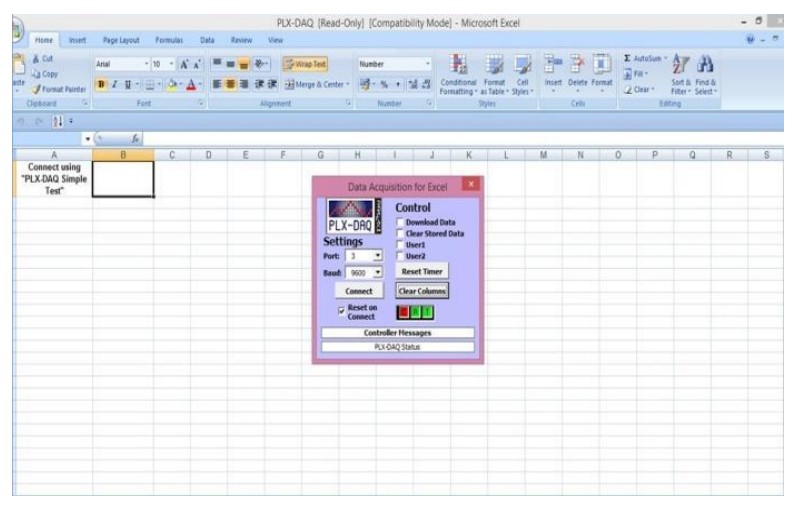

Figure 9 PLX-DAQ to read the data

The real time data read through the interface will be stored in an excel sheet. The data consists of the time of capture, temperature, humidity, gas and flame sensor values.

Table 1. Comparison of different techniques

\begin{tabular}{|l|l|l|}
\hline \multicolumn{1}{|c|}{$\begin{array}{c}\text { Related } \\
\text { work }\end{array}$} & \multicolumn{1}{|c|}{$\begin{array}{c}\text { Parameters } \\
\text { used }\end{array}$} & \multicolumn{1}{|c|}{ Sensors used } \\
\hline $\begin{array}{l}\text { Cheng } \text { et al. } \\
{[19]}\end{array}$ & Air Quality & $\begin{array}{l}\text { Electrochemical } \\
\text { gas sensor, Based } \\
\text { on Narrowband IoT }\end{array}$ \\
\hline $\begin{array}{l}\text { Kavitha } \text { et al. } \\
{[20]}\end{array}$ & $\begin{array}{l}\text { Smoke, carbon } \\
\text { monoxide, LPG, } \\
\text { methane }\end{array}$ & $\begin{array}{l}\text { MQ-6, MQ-7, MQ- } \\
135\end{array}$ \\
\hline $\begin{array}{l}\text { Kumar } \text { et al. } \\
{[21]}\end{array}$ & $\begin{array}{l}\text { Carbon } \\
\text { Monoxide, }\end{array}$ & $\begin{array}{l}\text { MQ9 gas sensor, } \\
\text { MQ2 sensor, }\end{array}$ \\
\hline
\end{tabular}

\begin{tabular}{|l|l|l|}
\hline & $\begin{array}{l}\text { Smoke and PM } \\
\text { level }\end{array}$ & $\begin{array}{l}\text { PMS3003 G3 } \\
\text { particle sensor }\end{array}$ \\
\hline $\begin{array}{l}\text { Swain et al. } \\
{[22]}\end{array}$ & $\begin{array}{l}\text { pH, temperature, } \\
\text { humidity and } \\
\text { concentration of } \\
\text { carbon monoxide }\end{array}$ & DHT -11, MG-811 \\
\hline $\begin{array}{l}\text { Yavari et al. } \\
{[23]}\end{array}$ & $\begin{array}{l}\text { Hydrocarbon in } \\
\text { water }\end{array}$ & $\begin{array}{l}\text { IoT hydrocarbon } \\
\text { sensor based on } \\
\text { silicone }\end{array}$ \\
\hline $\begin{array}{l}\text { Proposed } \\
\text { method }\end{array}$ & $\begin{array}{l}\text { Toxic gases } \\
\text { released, } \\
\text { temperature, air } \\
\text { pressure, } \\
\text { humidity and fire }\end{array}$ & $\begin{array}{l}\text { LM35 temperature } \\
\text { sensor, DHT22 } \\
\text { humidity sensor, } \\
\text { MQ-6 Gas Sensor, } \\
\text { Flame sensor }\end{array}$ \\
\hline
\end{tabular}

This data can be used to analyze the mining environment and take necessary action during catastrophes. Compared to other related works [19] and [20], the proposed model is more scalable and robust. Since the proposed system is built using commodity hardware, the system is more cost effective compared to the related works [18]. Most of the related work [21] [22] are concentrated on one particular environmental parameter like temperature, humidity, air, or flames, etc. The proposed model takes into account most of the environmental parameters required for monitoring safe and clean surroundings. Table 1 . Shows the comparison of parameters taken in different related works.

\section{CONCLUSION}

In coal mining industries, it is very important to take care of the safety of coal mine employees and reduce the likelihood of mishaps or unfortunate worker deaths. Automation and efficient communication through IoT technology has the potential to help a large number of individuals working in coal mines. The proposed work aims to contribute to the development of low-power, cost-effective solution for creating safe coal mining environment. The proposed coal mining protection system makes use of the Internet of Things technology to address various safety issues that occur in the mining environment. The sensors in the network will detect changes in the environment and will immediately send an alert or message to the end user requesting emergency assistance. The results show that the real-time data can be collected efficiently through this system and can be used to prevent accidents. The limitation of this work is the usage of vendor dependent tools and the implementation restricted to a virtual environment. The implementation was done in the laboratory environment with minimum usage of hardware equipment. This work can be extended to a real-time environment where a large number of sensors and devices are used. The data generated from a real-time environment will be huge and might require data analysis tools to handle large amounts of data. 


\section{REFERENCES}

[1] Ivan Alfonso, Camilo Gomez, Kelly Garces, Jaime Chayarriaga, "Lifetime Optimization of Wireless Sensor Networks for Gas Monitoring in Underground Coal Mining", 7th International Conference on Computers Communications and Control (ICCCC) ,2018, pp. 224-230.

[2] Mohd Anas, Syed Mohd Haider, Prateek Sharma, "Gas Monitoring and Testing in Underground Mines using Wireless Technology", International Journal of Engineering Research \& Technology, January-2017, vol6 issue 01. Pp. 412-416.

[3] Ramesh V., Gokularkrishnan V. J, Saravanan R, Manimaran R, "Integrated Mine Safety Altering System Using IOT with GSM", IJSRST, March/ April 2018, Vol. 4 Issue 5, pp. 200-206

[4] C. Qiang, S. J. Ping, Z. Zhe, Z. Fan, "ZigBee Based Intelligent Helmet for Coal Miners", Proc. IEEE World Congress on Computer Science and Information Engineering, pp. 433-35, 2019.

[5] D. Koenig, M. S. Chiaramonte, "Wireless Network for Measurement of Whole-Body Vibration", J. Sensors, vol. 8, pp. 3067-81, 2008.

[6] Kumarsagar, "Design of Monitoring system for Coal mine safety based on MSP430", International Journal of Engineering Science Invention(IJESI) Volume2, Issue 7, July 2013

[7] Kumar, "Design and Implementation of Portable health monitoring system using PSOC mixed signal Array chip". International Journal of Recent Technology and Engineering (IJRTE), ISSN, 2277$3878,2012$.

[8] Lihui, "Design of Monitoring system for Coal mine safety based on Wireless sensor Networks" 2008 International Conference on Mechatronic and Embedded systems and Applications (ASME).

[9] Madhu, "Coalmine safety monitoring system", International journal of Mechanical Engineering and Technology (IJMET) Volume 8,Issue 12 ,December 2017

[10] Ashish, "Coalmine safety monitoring using Wireless sensor Networks", International Journal of Scientific Engineering and Technology (IJSET) Volume 2, Issue 10, 2018.

[11] Wakode, "Coalmine safety monitoring and Alerting system", International research journal on Engineering and Technology (IRJET) Volume 4, Issue 3,March 2017

[12] J. Li, M. Li, F. Yan and D. Miao, "Key technologies of data monitoring for coal machinery equipment in the intelligent IOT environment," 2020 10th Institute of Electrical and Electronics Engineers International Conference on Cyber Technology in Automation, Control, and Intelligent Systems (CYBER), 2020, pp. 364369,doi:10.1109/CYBER50695.2020.9278951.

[13] Hesedahl, Jeanette; Hagedorn, Joe; Beiler, Todd; Ono, Chris, Inter-noise and noise-con congress and conference proceedings, NoiseCon20, New Orleans, LA, 2020, pp. 786-793(8)

[14] Stoyanova, Y. Nikoloudakis, S. Panagiotakis, E. Pallis and E. K. Markakis, "A Survey on the Internet of Things (IoT) Forensics: Challenges, Approaches, and Open Issues," in IEEE Communications Surveys \& Tutorials, vol. 22, no. 2, pp. 1191-1221, Secondquarter 2020, doi: 10.1109/COMST.2019.2962586

[15] Vinay Gupta, Madhu Sharma, Rupendra Kumar Pachauri and K. N. Dinesh, "A Low-Cost RealTime IOT Enabled Data Acquisition System for Monitoring of PV System, Energy Sources, Part A: Recovery, Utilization, and Environmental Effects", (2020) DOI: 10.1080/15567036.2020.1844351

[16] Supreetha and T. L. Pooja, "Automated Data Acquisition and Controlling System in Housing Line Using Internet of Things" Springer Nature Switzerland AG 2020 S. Smys et al. (Eds.): ICICIT 2020, LNNS 98, pp. 1-10, https://doi.org/10.1007/978-3-030-33846-6_1

[17] Aditi Nagrale, Roshani Wakodikar, Priti Nakade and Ketan Marothi, "Coal Mine Safety Monitoring and Alert System" International Journal of Advanced Research in Science, Communication and Technology, 2020, vol. 4, no. 3,DOI: 10.48175/IJARSCT-V4-I3-033

[18] M. Li and Y.-H. Liu, "Underground coal mine monitoring with wireless sensor networks," ACM Trans. Sens. New., vol. 5, no. 2, pp. 1-29, 2019.

[19] Yuanhang Cheng and Xueshu Xu, "Design of Air Quality Monitoring System Based on NB-IoT", 2019 IEEE International Conference on Power, Intelligent Computing and Systems (ICPICS).

[20] Kavitha.B.C and Vallikannu.R, "IoT Based Intelligent Industry Monitoring System”, 2019 6th International Conference on Signal Processing and Integrated Networks (SPIN).

[21] Ajitesh Kumar, Mona Kumari and Harsh Gupta, "Design and Analysis of IoT based Air Quality Monitoring System”, 2020 International Conference on Power Electronics \& IoT Applications in 
Renewable Energy and its Control (PARC) GLA University, Mathura, UP, India. Feb 28-29, 2020.

[22] Kunja Bihari Swain, G. Santamanyu and Amiya Ranjan Senapati, "Smart Industry Pollution Monitoring and Controlling using LabVIEW based IoT", 2017 IEEE 3rd International Conference on Sensing, Signal Processing and Security (ICSSS).

[23] Ali Yavari, Dimitrios Georgakopoulos, Paul R. Stoddart, Mahnaz Shafiei, "Internet of Things-based Hydrocarbon Sensing for Real-time Environmental Monitoring", 2019 IEEE 5th World Forum on Internet of Things (WF-IoT).

[24] Bhuvaneswary, N., S. Prabu, S. Karthikeyan, R. Kathirvel, and T. Saraswathi. "Low Power Reversible Parallel and Serial Binary Adder/Subtractor." Further Advances in Internet of Things in Biomedical and Cyber Physical Systems (2021): 151.

[25] Prabu, S., Balamurugan Velan, F. V. Jayasudha, P. Visu, and K. Janarthanan. "Mobile technologies for contact tracing and prevention of COVID-19 positive cases: a cross-sectional study." International Journal of Pervasive Computing and Communications (2020).

[26] K. Yu, Z. Guo, Y. Shen, W. Wang, J. C. Lin, T. Sato, "Secure Artificial Intelligence of Things for Implicit Group Recommendations", IEEE Internet of Things Journal, 2021, doi: 10.1109/JIOT.2021.3079574.

[27] Rajendran, Ganesh B., Uma M. Kumarasamy, Chiara Zarro, Parameshachari B. Divakarachari, and Silvia L. Ullo. "Land-use and land-cover classification using a human group-based particle swarm optimization algorithm with an LSTM Classifier on hybrid pre-processing remote-sensing images." Remote Sensing 12, no. 24 (2020): 4135.

[28] Hu, Liwen, Ngoc-Tu Nguyen, Wenjin Tao, Ming C. Leu, Xiaoqing Frank Liu, Md Rakib Shahriar, and SM Nahian Al Sunny. "Modeling of cloud-based digital twins for smart manufacturing with MT connect." Procedia manufacturing 26 (2018): 11931203.

[29] Seyhan, Kübra, Tu N. Nguyen, Sedat Akleylek, Korhan Cengiz, and SK Hafizul Islam. "Bi-GISIS KE: Modified key exchange protocol with reusable keys for IoT security." Journal of Information Security and Applications 58 (2021): 102788.

[30] Nguyen, Tu N., Bing-Hong Liu, Nam P. Nguyen, and Jung-Te Chou. "Cyber security of smart grid: attacks and defenses." In ICC 2020-2020 IEEE International Conference on Communications (ICC), pp. 1-6. IEEE, 2020.
[31] Subramani, Prabu, Ganesh Babu Rajendran, Jewel Sengupta, Rocío Pérez de Prado, and Parameshachari Bidare Divakarachari. "A block bidiagonalization-based pre-coding for indoor multiple-input-multiple-output-visible light communication system." Energies 13, no. 13 (2020): 3466.

[32] Rajendrakumar, Shiny, and V. K. Parvati. "Automation of irrigation system through embedded computing technology." In Proceedings of the 3rd International Conference on Cryptography, Security and Privacy, pp. 289-293. 2019.

[33] H. Li, K. Yu, B. Liu, C. Feng, Z. Qin and G. Srivastava, "An Efficient Ciphertext-Policy Weighted Attribute-Based Encryption for the Internet of Health Things," IEEE Journal of Biomedical and Health Informatics, 2021, doi: 10.1109/JBHI.2021.3075995.

[34] C. Feng et al. "Efficient and Secure Data Sharing for 5G Flying Drones: A Blockchain-Enabled Approach," IEEE Network, vol. 35, no. 1, pp. 130137, January/February 2021, doi: 10.1109/MNET.011.2000223.

[35] N. Shi, L. Tan, W. Li, X. Qi, K. Yu, “A BlockchainEmpowered AAA Scheme in the Large-Scale HetNet", Digital Communications and Networks, https://doi.org/10.1016/j.dcan.2020.10.0 02.

[36] Y. Sun, J. Liu, K. Yu, M. Alazab, K. Lin, "PMRSS: Privacy-preserving Medical Record Searching Scheme for Intelligent Diagnosis in IoT Healthcare", IEEE Transactions on Industrial Informatics, doi: 10.1109/TII.2021.3070544.

[37] Z. Guo, L. Tang, T. Guo, K. Yu, M. Alazab, A. Shalaginov, "Deep Graph Neural Network-based Spammer Detection Under the Perspective of Heterogeneous Cyberspace", Future Generation Computer Systems, https://doi.org/10.1016/j.future.2020.11.028. 